\title{
Impact of inulin and oligofructose on gastrointestinal peptides
}

\author{
Nathalie M. Delzenne*, Patrice D. Cani, Catherine Daubioul and Audrey M. Neyrinck \\ Unit of Pharmacokinetics, Metabolism, Nutrition and Toxicology, MD/FARM/PMNT 7369, Université Catholique de Louvain, Avenue E \\ Mounier 73, B-1200 Brussels, Belgium
}

In the present paper, we summarise the data supporting the following hypothesis: dietary inulin-type fructans extracted from chicory root may modulate the production of peptides, such as incretins, by endocrine cells present in the intestinal mucosa, this phenomenon being involved in the regulation of food intake and/or systemic effects. To test this hypothesis, male Wistar rats received for 3 weeks either a standard diet or the same diet supplemented with $10 \%$ inulin-type fructans with different degrees of polymerisation. All the effects were most pronounced with the diet containing oligofructose, and consisted of (i) a decrease in mean daily energy intake and in epididymal fat mass; (ii) a higher caecal pool of the anorexigenic glucagon-like peptide-1 (736) amide (GLP-1), and peptide YY (PYY), due to caecal tissue proliferation; (iii) an increase in GLP-1 and of its precursor - proglucagon mRNA concentrations in the proximal colon; (iv) an increase in portal serum level of GLP-1 and PYY; (v) a decrease in serum orexigenic peptide ghrelin. Moreover, oligofructose supplementation improved glucose homeostasis (i.e. decreased glycaemia, increased pancreatic and serum insulin content) in diabetic rats previously treated with streptozotocin, a phenomenon that is partly linked to the reduction in food intake and that correlates with the increase in colic and portal GLP-1 content. Based on these results it appears justified to test, in human subjects, the hypothesis that dietary inulin-type fructans could play a role in the management of obesity and diabetes through their capacity to promote secretion of endogenous gastrointestinal peptides involved in appetite regulation.

Oligofructose: Glucagon-like peptide-1: Peptide YY: Ghrelin: Rats

Inulin-type fructans have recently been recognised as interesting dietary fibres, not only able to improve intestinal functions through their prebiotic properties but also to exert beneficial systemic effects (Roberfroid \& Delzenne, 1998; Delzenne, 2003).

In our laboratory, we have shown that the addition of inulintype fructans at the dose of $10 \%(\mathrm{w} / \mathrm{w})$ in the diet for several weeks decreases triacylglycerol accumulation in the liver and epididymal fat mass, both in normal and obese Zucker falfa rats (Daubioul et al. 2000, 2002). In the normal rat, this effect is linked to a decrease in hepatic lipogenesis and a decrease in postprandial triglyceridaemia (Delzenne \& Kok, 2001). In obese rats, the administration of oligofructose (for the description of the different inulin-type fructans, see the paper by Roberfroid in this supplement), and also of oligofructose-enriched inulin is clearly responsible for an improvement of steatosis (Daubioul et al. 2002). Most of the effects of inulin-type fructans on lipid metabolism correlated with a decrease in food-derived energy intake, mainly due to a lower calorific value of the fructans-containing diet. Normally, rats compensate for the lower calorific value of the diet by increasing the daily amount of ingested diet: in the Zucker rat, the addition of $10 \%$ cellulose in the diet did not protect rats against steatosis because cellulose-treated rats ate about $10 \%$ more diet per day during the treatment (Daubioul et al. 2002). This led us to postulate that the addition of inulin-type fructans was able to help reduce food intake - and subsequently fat mass development - in animals. However, a fundamental question remains to be answered: how do, from a mechanistic point of view, non-digestible/fermentable fibres, such as inulin-type fructans, exert a satiating effect?

Involvement of gastrointestinal peptides in the regulation of food intake by dietary inulin-type fructans: from theory to experimental data

Endocrine cells present in the intestinal mucosa secrete peptides involved in the regulation of food intake and/or pancreatic functions - the latter being called incretins (Druce et al. 2004; Stanley et al. 2004). Endocrine L-cells are distributed all along the intestinal tract and are also mostly present in the caeco-colon, where fermentation of inulin-type fructans occurs (Drucker, 2002). Lcells secrete several peptides, derived from the expression of the proglucagon gene, followed by the selective cleavage of the peptide through the action of pro-hormone convertase $1 / 3$; posttranslational modification leads to the production of glucagonlike peptide-1 (7-36) amide (GLP-1), GLP-2, oxyntomodulin, glicentin and intervening peptide-2 (Drucker, 2002; Stanley et al. 2004). L-cells also produce peptide YY (1-36) amide from the $P Y Y$ gene, this peptide being cleaved by dipeptidylpeptidase IV into PYY (3-36) amide (PYY).

Among those peptides, GLP-1, oxyntomodulin and PYY have recently been proposed as important modulators of appetite through their peripheral effect (vagal nerve) and/or by acting directly on the arcuate nucleus (Druce et al. 2004; Stanley et al. 2004). GLP-1 is also involved in the regulation of pancreatic 
secretion of insulin and in the differentiation and maturation of $\beta$ cells (Brubaker \& Drucker, 2004).

The facts that:

(1) those peptides are mainly produced in the lower part of the gut, where non-digestible oligosaccharides including inulin-type fructans are largely fermented,

(2) the products of such a fermentation in the gut - namely, SCFA - are known to increase the expression of proglucagon in the intestinal tissue (Tappenden et al. 1998; Drozdowski et al. 2002) and

(3) some dietary fibres are able to increase proglucagon expression when given at high doses in the diet of dogs or rats (Reimer \& McBurney, 1996; Massimino et al. 1998),

led us to verify the production of gut peptides in the different segments of the intestine of rats receiving inulin-type fructans in their diet. Subsequently, we also correlated incretin production with the modulation of food intake, fat mass development, and, in a model of diabetic rats, we assessed parameter markers of the pancreatic function.

\section{Effects of inulin-type fructans in normal rats}

We first compared the influence of inulin-type fructans with different degrees of polymerisation, namely oligofructose, oligofructose-enriched inulin and high-molecular-weight inulin, on GLP-1 and PYY production. The concentration of these peptides, and of the corresponding mRNA precursor, was measured in the different segments of the intestinal tract in male Wistar rats having received the fructans at a dose of $10 \%$ (w/w in diet) for 3 weeks. All measurements were performed $8 \mathrm{~h}$ after removal of the diet. GLP-1 content - but also proglucagon mRNA was increased in the proximal colon of rats receiving oligofructose-containing diets. The short-chain inulin-type fructans, which are most extensively fermented in the caecum and in the proximal colon, were more potent to induce this effect (Fig. 1; Cani et al. 2004a). Surprisingly, there was no modification of PYY protein or mRNA in the different intestinal segments, thus suggesting that the effect of oligofructose was linked to a specific effect on proglucagon gene expression in L-cells. Interestingly, the enlargement of the caecal tissue was responsible for an increase in the total caecal pool of both GLP-1 and PYY. As shown in Table 1, portal concentration of both peptides was almost doubled after oligofructose treatment. This is quite interesting since it means that increased flux of those peptides can reach the portal vagal 'sensors', acting as a potential signal to the hypothalamic centres that control food intake (Schwartz, 2000). A recent study has suggested that portal GLP-1 might also influence the production of ghrelin (Lippl et al. 2004), which was identified in 1999 as a peptide secreted by the endocrine cells of the stomach, stimulating feeding behaviour, lowering energy expenditure and driving body weight increase due to a change in fuel partitioning (Kojima et al. 1999; Tschop et al. 2000). The plasma ghrelin level was 443.9 (SD 25) $\mathrm{pg} / \mathrm{ml}$ in control rats, and was significantly lowered to reach 306.9 (SD 24.2) $\mathrm{pg} / \mathrm{ml}$ and 293.9 (SD 42.4) $\mathrm{pg} / \mathrm{ml}$ in oligofructose-fed rats, and oligofructose-enriched inulin-fed rats, respectively. This suggests that a lower ghrelin production can also contribute to a decrease in appetite during fasting. These results are in line with the modifications of the dietary intake pattern observed in rats fed inulin-type fructans, as well as with their effect on fat
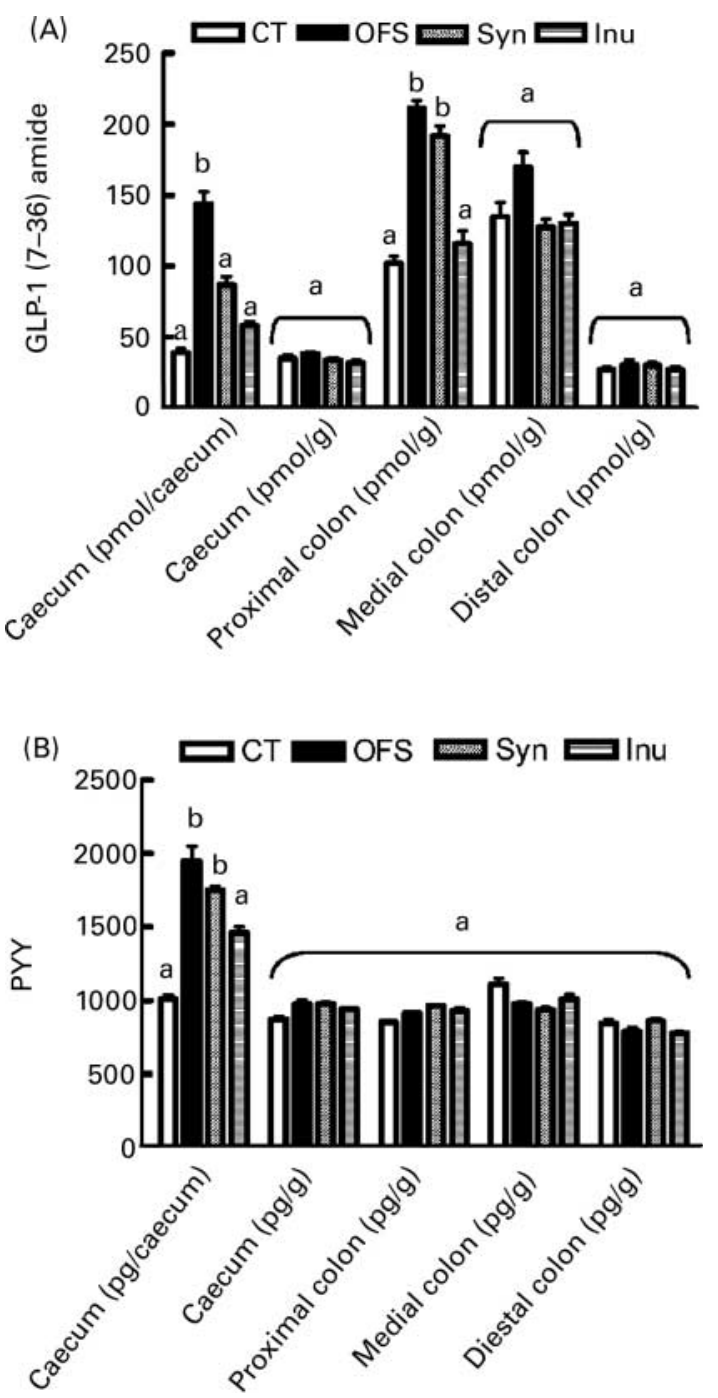

Fig. 1. Intestinal glucagon-like peptide-1 (GLP-1) (7-36) amide (A) and peptide $Y Y(P Y Y)(B)$ concentration in rats fed a control diet (CT) or a diet supplemented with oligofructose (OFS), oligofructose-enriched inulin (Syn) or high-molecular-weight inulin (Inu). Values are means, with standard errors of mean represented by vertical bars, six animals per group; statistical analysis has been performed through one-way ANOVA followed by Tukey's test, separately for each organ. For each organ, mean values with unlike superscript letter are significantly different: $P<0 \cdot 05$. (Adapted from Cani et al. 2004a.

mass development. Indeed the epididymal fat mass was lowered by about $30 \%$ in oligofructose-fed rats as compared to controls. Until now the mechanisms of these effects remain unknown.

\section{Effects of inulin-type fructans in diabetic rats}

The results obtained in normal rats demonstrated that oligofructose was the most potent inulin-type fructan in terms of GLP-1 production in the intestinal tissue. GLP-1 (7-36) amide is considered a key peptide in the control of glucose-dependent insulin release by pancreatic $\beta$-cells. Moreover, it is also responsible for an increased $\beta$-cells neogenesis in streptozotocin (STZ)-treated newborn rats a model of diabetes - thus allowing a partial recuperation of pancreatic function with age (Tourrel et al. 2001).

We decided to investigate the effects of oligofructose feeding in growing rats treated with intravenous injection of STZ at a dose of 
Table 1. Portal glucagon-like peptide-1 (7-36) amide (GLP-1) and peptide YY (3-36) (PYY) amide concentrations of rats fed a control diet (CT) or a diet supplemented with oligofructose (OFS), oligofructose-enriched inulin (Syn) or high-molecular-weight inulin (Inu) (adapted from Cani et al. 2004) (Mean values and standard errors of the mean for six animals per group)

\begin{tabular}{|c|c|c|c|c|}
\hline & \multicolumn{4}{|c|}{ Portal vein peptides } \\
\hline & \multicolumn{2}{|c|}{ GLP-1 (7-36) amide (рм) } & \multicolumn{2}{|c|}{ PYY (3-36) amide $(\mathrm{pg} / \mathrm{ml})$} \\
\hline & Mean & SEM & Mean & SEM \\
\hline CT & $7 \cdot 8^{\mathrm{a}}$ & 0.7 & $42 \cdot 7^{\mathrm{a}}$ & $8 \cdot 2$ \\
\hline OFS & $11 \cdot 4^{\mathrm{b}}$ & $1 \cdot 2$ & $84 \cdot 9^{b}$ & $10 \cdot 3$ \\
\hline Syn & $10 \cdot 5^{\mathrm{b}}$ & 1.7 & $55 \cdot 7^{\mathrm{a}}$ & 11.0 \\
\hline Inu & $8 \cdot 4^{a}$ & $1 \cdot 3$ & $48 \cdot 3^{a}$ & 13.9 \\
\hline
\end{tabular}

Statistical analysis has been performed through one-way ANOVA followed by Tukey's test, separately for each peptide. Mean values sharing the same superscript letter are not significantly different: $P<0.05$.

$30-40 \mathrm{mg} / \mathrm{kg}$ body weight. The results are submitted for publication and can be summarised as follows: 1 week after the STZ treatment, rats were selected based on their glycaemia (between 15 and $35 \mathrm{~mm}$ ), and randomised into three experimental groups, namely:

(1) An STZ-control group, receiving the standard A04 diet;

(2) An STZ-OFS group, receiving a diet containing $10 \%$ oligofructose;

(3) An STZ-restriction group that was food-restricted in order to receive the same amount of diet compared to the non-diabetic animals (treated with citrate in place of STZ, and receiving the control A04 diet throughout the treatment).

Oligofructose treatment reduced, to a large extent, all symptoms associated with diabetic state (postprandial hyperglycaemia, hyperphagia, polydypsia, weight loss) normally observed in STZ-treated animals (Cani et al. 2004b). The drastic dietary restriction only partially explains the improvement of glycaemia in those conditions. Interestingly, a prolonged oligofructose treatment ( 6 weeks) allows a partial restoration of the pancreatic insulin content and brings back to normal percentage values of $\beta$-cells in the pancreatic tissue, as well as postprandial insulinaemia (Cani et al. 2004b). Since oligofructose treatment was able to both reduce food intake and improve glucose metabolism in STZ-diabetic rats, we have analysed GLP-1 content in the different parts of the intestine and in the portal vein of the animals (Table 2). Surprisingly, 4 weeks after STZ injection, the ileal concentration of GLP-1 was higher in rats receiving the standard diet than in rats receiving the diet containing oligofructose, or food-restricted. This would mean that hyperphagia, and consequently, the large amount of nutrients reaching the gut, increase the GLP-1 content in the ileal tissue; however, no modification of proglucagon mRNA content was observed (data not shown), thus leading us to postulate that the mechanism of the ileal overproduction of GLP-1 in diabetic rats is not due to an increase in gene expression. This is in accordance with the results of Nie et al. (2000), suggesting that the increase in GLP-1 in the pancreatic tissue of STZ-treated rats was rather due to an increase in pro-hormone convertase $1 / 3$ activity than to a modulation of proglucagon expression. Both colic and portal concentration of GLP-1 were increased in STZ animals, but to a greater extent in oligofructose-treated rats than in rats receiving the standard diet (Table 2). From those experiments, we may suggest that the pre-
Table 2. Concentration of glucagon-like peptide-1 (7-36) amide (GLP-1) in the portal vein, ileal and colonic intestinal segments in control (CT) rats, streptozotocin-treated control (STZ-CT) rats, streptozotocin-treated rats receiving a $10 \%$ oligofructose diet (STZ-OFS) and streptozotocin-treated food-restricted (STZ-Res) rats

(Mean values and standard errors of the mean for five animals per group)

\begin{tabular}{|c|c|c|c|c|c|c|}
\hline & \multicolumn{6}{|c|}{ GLP-1 (7-36) amide concentration } \\
\hline & \multicolumn{2}{|c|}{ Portal (рм) } & \multicolumn{2}{|c|}{ Ileal (pmol/g) } & \multicolumn{2}{|c|}{$\begin{array}{c}\text { Colonic } \\
(\mathrm{pmol} / \mathrm{g})\end{array}$} \\
\hline & Mean & SEM & Mean & SEM & Mean & SEN \\
\hline CT & 10.04 & 0.45 & 74 & 21 & 107 & 15 \\
\hline STZ-CT & $26 \cdot 4^{*}$ & $4 \cdot 25$ & 246 & 26 & $219^{*}$ & 52 \\
\hline STZ-OFS & $40 \cdot 11^{*}$ & $12 \cdot 47$ & $181^{*} \dagger \ddagger$ & 13 & $276^{\star}$ & 12 \\
\hline STZ-Res & $13 \cdot 12$ & 0.56 & $132^{*}$ & 21 & 170 & 43 \\
\hline
\end{tabular}

${ }^{*} P<0.05$ v. CT

$\dagger P<0.05$ v. STZ-CT.

$\ddagger P<0.05$ v. STZ-Res.

sence of oligofructose in the diet of rats previously treated with STZ improves glucose homeostasis (decrease in glycaemia, increase in pancreatic and serum insulin), a phenomenon partially dependent on food restriction. The involvement of colonic GLP-1 in the effects is likely, even if diabetic rats fed a standard diet also exhibit a higher intestinal GLP-1 content. This latter effect could be seen as a putative 'compensatory' mechanism that might be amplified (or accelerated?) by oligofructose. A recent study has also tested the influence of oligofructose in another model of diabetes (type 1 diabetes mellitus induced by dietary proteins in the diabetes-prone BB rat; Perrin et al. 2003). The authors have shown that at the concentration of $5 \%$ in the diet, oligofructose did not modify, when compared to cellulose, the incidence of pancreatic alterations. The dose of oligofructose as well as the origin of the alteration of pancreatic cells (autoimmune disease in the prone diabetic rats) is different, a fact that might explain the discrepancies between results. However, we may also postulate that the effectiveness of the oligofructose treatment may depend on its satiating effect, and on its effect on incretins production, which has not been reported in other studies. These could be key parameters to measure in the future.

Further studies are needed to assess the implication of GLP-1 on the effects of oligofructose, i.e. by analysing its influence on GLP-1 receptors in knockout mice (Burcelin et al. 2001).

\section{Conclusions and perspectives: from the molecular basis towards human health}

Figure 2 summarises the effects of oligofructose on intestinal incretins based on our data. In conclusion, we confirm that oligofructose in the diet of rats increases the availability of GLP-1 coming from the caeco-colon. The molecular mechanism remains to be fully elucidated, but in view of our data we propose that an increased production of the precursor proglucagon mRNA is a key event. Recent papers, based both on in vitro and in vivo studies in animals, suggest a role of SCFA in the regulation of the expression of the intestinal proglucagon gene (Tappenden et al. 1998; Drozdowski et al. 2002). Since fermentation of oligofructose and of other nondigestible/fermentable carbohydrates, such as resistant starch or galactooligosaccharides, produces a specific profile of SCFA, it would be interesting to correlate the pattern of fermentation in situ 


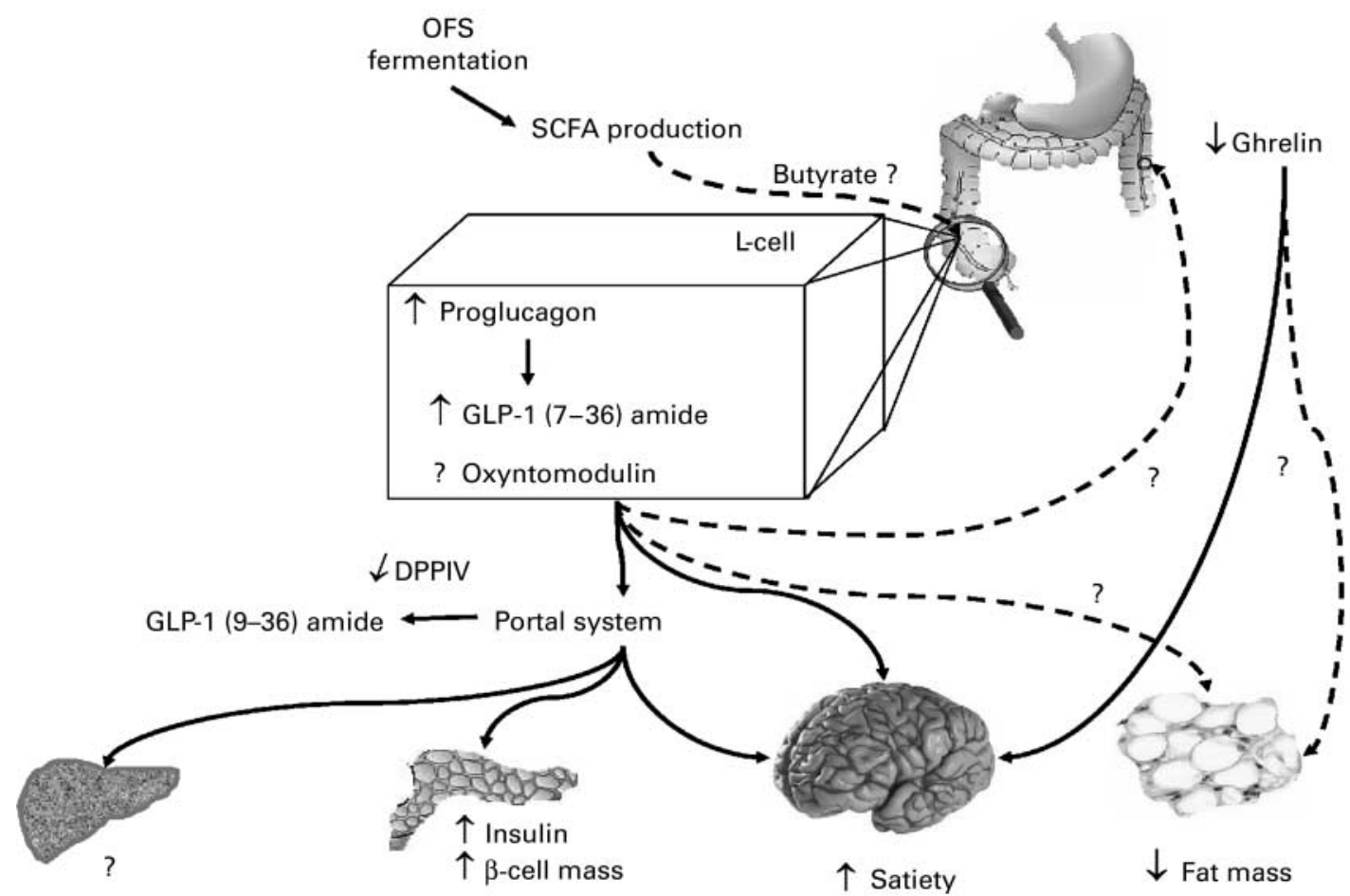

Fig. 2. Effects of oligofructose on gastrointestinal peptides. OFS, oligofructose; GLP-1, glucagon-like peptide-1; DPPIV, dipeptidylepeptidase IV.

(i.e. proximal colon) with the putative effect on GLP-1 production and expression. But other mechanisms to explain a higher portal GLP-1 after oligofructose treatment cannot be excluded because we have also shown that the activity of serum dipeptidylpeptidase IV - responsible for GLP-1 cleavage and inactivation - is decreased during oligofructose treatment.

Even if GLP-1 appears as a good candidate to explain some physiological effects of inulin-type fructans (satiety, glucose homeostasis), other peptides could also be relevant, such as PYY or ghrelin, which were modulated by the treatment, as shown earlier. Oxyntomodulin could also be involved, since it has recently been proposed as a promising proglucagon-derived gut peptide in the control of food intake (Druce et al. 2004). Based on these results, it appears justified to test, in human subjects, the hypothesis that dietary inulin-type fructans could play a role in the management of obesity and diabetes. Other non-digestible/fermentable carbohydrates are prone to ameliorate postprandial glycaemia and insulin sensitivity in healthy human subjects (Robertson et al. 2003). Fermentation has been proposed to be involved in such a protective effect of resistant starch, and in view of our results, it would be interesting to assess the involvement of GLP-1 as a putative mediator of resistant starch also. One study has already reported that treatment of human volunteers with about $20 \mathrm{~g}$ oligofructose/d for $7 \mathrm{~d}$ was able to increase serum GLP-1 (Piche et al. 2003). Further analysis of the effect of dietary intake of inulin-type fructans (mainly oligofructose-containing products) on incretins production, appetite regulation and glucose metabolism in man are thus expected to bring interesting results.

\section{References}

Brubaker PL \& Drucker DJ (2004) Glucagon-like peptides regulate cell proliferation and apoptosis in the pancreas, gut and central nervous system. Endocrinology 145, 2653-2659.
Burcelin R, Da Costa A, Drucker D \& Thorens B (2001) Glucose competence of the hepatoportal vein sensor requires the presence of an activated glucagon-like peptide-1 receptor. Diabetes 50, 1720-1728.

Cani PD, Dewever C, \& Delzenne NM (2004a) Inulin-type fructans modulate gastrointestinal peptides involved in appetite regulation (glucagon-like peptide-1 and ghrelin) in rats. Br J Nutr 92, 521-526.

Cani PD, Daubioul C, Reusens B, Remacle C, Catillon G, \& Delzenne NM (2004b). Involvement of food restriction and endogenous GLP-1 (7-36) amide in glycemia-lowering effect of dietary oligofructose in streptozotocin diabetic rats. Regul Pept 122, 12-13 Abstr.

Daubioul C, De Wispelaere L, Taper H \& Delzenne N (2000) Dietary oligofructose lessens hepatic steatosis, but does not prevent hypertriglyceridemia in obese Zucker rats. J Nutr 130, 1314-1319.

Daubioul C, Rousseau N, Demeure R, Gallez B, Taper H, Declercq B \& Delzenne N (2002) Dietary fructans, but not cellulose, decrease triglyceride accumulation in the liver of obese Zucker falfa rats. $J$ Nutr 132, 967-973.

Delzenne N (2003) Oligosaccharides: state of the art. Proc Nutr Soc 62, $177-182$

Delzenne N \& Kok N (2001) Effects of fructans-type prebiotics on lipid metabolism. Am J Clin Nutr 73, 456S-458S.

Drozdowski LA, Dixon WT, McBurney MI \& Thomson AB (2002) Shortchain fatty acids and total parenteral nutrition affect intestinal gene expression. J Parenter Enteral Nutr 26, 145-150.

Druce MR, Small CJ \& Bloom SR (2004) Gut peptides regulating satiety. Endocrinology 145, 2660-2665.

Drucker DJ (2002) Biological actions and therapeutic potential of the glucagon-like peptides. Gastroenterology 122, 531-544.

Kojima M, Hosoda H, Date Y, Nakazato M, Matsuo H \& Kangawa K (1999) Ghrelin is a growth-hormone-releasing acylated peptide from stomach. Nature 402, 656-660.

Lippl F, Kircher F, Erdmann J, Allescher HD \& Schusdziarra V (2004) Effect of GIP, GLP-1, insulin and gastrin on ghrelin release in the isolated rat stomach. Regul Pept 119, 93-98.

Massimino SP, McBurney MI, Field CJ, Thomson AB, Keelan M, Hayek MG \& Sunvold GD (1998) Fermentable dietary fiber increases GLP-1 
secretion and improves glucose homeostasis despite increased intestinal glucose transport capacity in healthy dogs. J Nutr 128, 1786-1793.

Nie Y, Nakashima M, Brubaker PL, Li QL, Perfetti R, Jansen E, Zambre Y, Pipeleers D \& Friedman TC (2000) Regulation of pancreatic PC1 and PC2 associated with increased glucagon-like peptide 1 in diabetic rats. J Clin Invest 105, 955-965.

Perrin IV, Marchesini M, Rochat FC, Schiffrin EJ \& Schilter B (2003) Oligofructose does not affect the development of type 1 diabetes mellitus induced by dietary proteins in the diabetes-prone BB rat model. Diabetes Nutr Metab 16, 94-101.

Piche T, des Varannes SB, Sacher-Huvelin S, Holst JJ, Cuber JC \& Galmiche JP (2003) Colonic fermentation influences lower esophageal sphincter function in gastroesophageal reflux disease. Gastroenterology 124, 894-902.

Reimer RA \& McBurney MI (1996) Dietary fiber modulates intestinal proglucagon messenger ribonucleic acid and postprandial secretion of glucagon-like peptide-1 and insulin in rats. Endocrinology 137, 3948-3956.

Roberfroid MB \& Delzenne NM (1998) Dietary fructans. Аппи Rev Nutr 18, $117-143$.
Robertson MD, Currie JM, Morgan LM, Jewell DP \& Frayn KN (2003) Prior short-term consumption of resistant starch enhances post-prandial insulin sensitivity in healthy subjects. Diabetologia 46, 659-665.

Schwartz GJ (2000) The role of gastrointestinal vagal afferents in the control of food intake: current prospects. Nutrition 16, 866-873.

Stanley S, Wynne K \& Bloom S (2004) Gastrointestinal satiety signals III. Glucagon-like peptide 1, oxyntomodulin, peptide YY, and pancreatic polypeptide. Am J Physiol (Gastrointest Liver Physiol) 286, G693-G697.

Tappenden KA, Drozdowski LA, Thomson AB \& McBurney MI (1998) Short-chain fatty acid-supplemented total parenteral nutrition alters intestinal structure, glucose transporter 2 (GLUT2) mRNA and protein, and proglucagon mRNA abundance in normal rats. Am J Clin Nutr $\mathbf{6 8}$, $118-125$.

Tourrel C, Bailbe D, Meile MJ, Kergoat M \& Portha B (2001) Glucagonlike peptide-1 and exendin-4 stimulate beta-cell neogenesis in STZtreated newborn rats resulting in persistently improved glucose homeostasis at adult age. Diabetes 50, 1562-1570.

Tschop M, Smiley DL \& Heiman ML (2000) Ghrelin induces adiposity in rodents. Nature 407, 908-913. 